\title{
ETIOLOGIA DA PORNOGRAFIA INFANTIL: UM OLHAR CRÍTICO SOBRE A (CYBER)PEDOFILIA ${ }^{1}$
}

\author{
ETIOLOGY OF CHILD PORNOGRAPHY: A CRITICAL LOOK AT (CYBER) \\ PEDOPHILIA
}

Kalita Macêdo Paixão²

\begin{abstract}
RESUMO: Em contexto de graves violações e demanda de expansão de aparatos jurídicos-institucionais de proteção, o artigo trata de um estudo qualitativo a partir de dados de investigação criminal coletados junto à Polícia Federal da Bahia, destacando organização criminosa para fins de pornografia infantil com recorte temporal de 2017 a 2019. Através do estabelecimento de premissas originárias da conduta-crime, discorremos a respeito da incidência dessa lesão aos direitos sexuais de vulneráveis no espaço cibernético. Tal delimitação materializa o uso do aparelhamento acadêmico como promotor do desenvolvimento científico, vertente crítica e educativa, no que tange à efetividade dos meios combativos. Traz abordagem multidisciplinar voltada à adaptabilidade das normas jurídicas em relação às formas criminológicas contemporâneas. Objetiva a compreensão dos elementos descritivos e críticos essencialmente envolvidos na produção e consumo da pornografia infantil através do método dialético de forma qualitativa ex-post-facto exploratória. Como procedimentos, envolve coleta de dados dentro e fora de campo e realiza recorte epistemológico e teórico sob as lentes de gênero. A pesquisa empírica revela a necessidade interpretação feminista de sua incidência e da incorporação de políticas públicas efetivas através deste mesmo engajamento.
\end{abstract}

Palavras-Chave: pornografia; vulneráveis; crimes sexuais; crimes cibernéticos;

Abstract: In the context of serious violations and the demand for expansion of legalinstitutional protection devices, the article deals with a qualitative study based on criminal investigation data collected from the Federal Police of Bahia, highlighting a criminal organization for the purposes of child pornography with timeframe from 2017 to 2019. Through the establishment of premises originating from criminal conduct, we discuss the incidence of this injury to the sexual rights of vulnerable people in cyberspace. Such delimitation materializes the use of academic equipment as a promoter of scientific development, critical and educational, with regard to the effectiveness of combative means. It brings a multidisciplinary approach aimed at the adaptability of legal norms in relation to contemporary criminological forms. It aims to understand the descriptive and critical elements essentially involved in the production and consumption of child pornography through the dialectic method in a qualitative, ex-post exploratory way. As procedures, it involves data collection inside and outside the field and performs an epistemological and theoretical approach under the gender lens. Empirical research reveals the need for feminist interpretation of its incidence and the incorporation of effective public policies through this same engagement.

\footnotetext{
${ }^{1}$ Artigo proveniente de pesquisa desenvolvida como trabalho de conclusão de curso em Direito (2019), orientado pela Prof $\stackrel{a}{\text { a }}$. Dr ${ }^{\mathrm{a}}$ Vanessa Ribeiro Simon Cavalcanti.

${ }^{2}$ Bacharel em Direito e Pós-graduanda em Ciências Criminais. Email: kalitampaixao@gmail.com
} 
Keywords: pornography; vulnerable; sexual crimes; cyber crimes;

\section{INTRODUÇÃO}

Ao analisar as circunstâncias da incidência do crime previsto no artigo 241-A do Estatuto da Criança e Adolescente (ECA), referente à cyber publicação de registros pornográficos envolvendo àqueles amparados pela lei, estabelecem-se conexões interdisciplinares no tocante ao contexto criminológico e etiológico em questão. Conclui-se pela deteç̧ão de particularidades na conduta crime, concernentes tanto ao sujeito ativo quanto passivo, através do estudo psicossocial sob a ótica do gênero, que se mostra essencial para a compreensão da tipicidade apurada, e consequentemente, seu enfrentamento e combate.

Sob o aspecto penal, a lei busca uma adequação aos moldes contemporâneos da ação delituosa, já que falamos de um cybercrime. Contudo, apesar das denúncias serem crescentes, a polícia não tem alcançado os produtores do conteúdo, que além do interesse na satisfação da lascívia pela da exposição da criança pré-púbere, chegam a abusá-la sexualmente para o objetivo-fim da exploração - como ocorre no inquérito mencionado adiante.

Desassociando a raiz do comportamento investigado da pedofilia, ao compreender melhor a definição legal e a psicológica dos conceitos evolvidos, somos levados a buscar novas origens etiológicas para o ímpeto envolto no prazer sexual na figura infanto-juvenil.

Para isso, as subsequentes constatações tornam-se fundamentais, ao verificarem o predomínio do gênero masculino dos autores e feminino das vítimas de abuso e exploração sexual de menores, mostrando o gênero como fator de opressão e vulnerabilidade, respectivamente.

Nesse processo de definição dos papéis de autor e vítima do ato criminoso, comportamentos culturais enraizados revelam-se essenciais para a manutenção de tais violências. A indústria pornográfica e o conceito consolidado de beleza são exemplos claros do que acaba por conduzir a sociedade ao estabelecimento de parâmetros problemáticos determinantes para o fenômeno. 
Pelo prisma feminista, conexões chave podem ser feitas para consolidar a relação entre a opressão que sofrem as meninas prematuramente sexualizadas e os ideais sexistas na opressão da mulher no geral. $O$ entendimento tem base nas relações patriarcais de poder e dominação, que se desenvolvem ao passo que se acumulam os citados fatores de vulnerabilidade.

Nesse cenário, concomitantemente, nota-se um movimento combativo pautado em uma compreensão superficial da etiologia da incidência penal, que coloca a transgressão em um âmbito de julgamento moral totalmente equivocado. conservadorismo arcaico e o positivista, além de não abarcar a real problemática a ser enfrentada, se revela parte de um sistema que favorece a perpetuação de violências de cunho sexual.

\section{A PERSECUÇÃO CRIMINAL INQUISITORIAL}

Já na década de 1950 a infância deveria estar integralmente protegida em seus múltiplos e diversificados contextos, sendo resguardados todos os direitos consensuadas e pactuados internacionalmente, declarando as décadas vindouras como fomentadoras dessa proteção, para e pelos Direitos Humanos (CAVALCANTI; SILVA, 2018 e 2015). Todavia, apesar de que mesmo em caráter internacional é-se instituída legalmente tal tutela, os números indicam alta incidência de violência de cunho sexual contra crianças e adolescentes.

Em levantamento realizado pela plataforma de denúncias de crimes cibernéticos Safernet, apontou-se que a pornografia infantil fora o crime mais relatado no ano de $2019^{3}$, ressaltando, contudo, que mesmo que os números de denúncias se mostrem crescentes, a polícia tem identificado, majoritariamente, apenas os que compartilham 0 material ${ }^{4}$. Houveram quase 50 mil denúncias, seguidas de

${ }^{3}$ SAFERNET BRASIL. Indicadores da Central de Denúncias de Crimes Cibernéticos. Disponível em: https://indicadores.safernet.org.br/index.html, acesso em 08/01/2020.

4 EXAME. Brasil. "Combate à pornografia infantil cresce, mas não atinge produtores". Estadão Conteúdo, 2018. Disponível em: https://exame.abril.com.br/brasil/combate-a-pornografia-infantilcresce-mas-nao-atinge-produtores/, acesso em: 24/10/2019. 
aproximadamente 8 mil de apologia e incitação à violência e crimes contra a vida, e 7 mil de violência contra mulheres ou misoginia.

Com a constatação da alta incidência criminal, mesmo em um contexto onde o Estado estaria, teoricamente, exercendo uma postura protetiva, pode-se supor a existência de "pontos cegos" no sistema consolidado de justiça "pós-democrático", onde o discurso humanista atual acoberta questões relevantes aos direitos humanos, em detrimento das lógicas do neoliberalismo (ESTEVAO, 2013), que se revelariam justificativa para a inefetividade da lei penal.

\subsection{DOS CRIMES CONTRA A CRIANÇA E ADOLESCENTE}

Pode-se verificar, preliminarmente, que o inquérito em curso na DELINST - PF/BA, utilizado como base exemplificativa da pesquisa, se resume à incidência penal dos arts. 241-A e 241-B, do Estatuto da Criança e Adolescente. Observa-se que os delitos, sendo o primeiro referente à divulgação e o segundo à aquisição de registros pornográficos envolvendo crianças e adolescentes, são crimes cibernéticos que tutelam os direitos sexuais desse grupo socialmente vulnerável. Diz a Lei oㅡ 8.069 de 13 de julho de 1990 :

Art. 241-A. Oferecer, trocar, disponibilizar, transmitir, distribuir, publicar ou divulgar por qualquer meio, inclusive por meio de sistema de informática ou telemático, fotografia, vídeo ou outro registro que contenha cena de sexo explícito ou pornográfica envolvendo criança ou adolescente: (Incluído pela Lei no 11.829, de 2008). (grifos meus)

Art. 241-B. Adquirir, possuir ou armazenar, por qualquer meio, fotografia, vídeo ou outra forma de registro que contenha cena de sexo explícito ou pornográfica envolvendo criança ou adolescente: (Incluído pela Lei no 11.829, de 2008). (grifos meus)

A legislação brasileira repreende também o registro e reprodução, a venda e simulação de cena de sexo explícito ou pornográfica envolvendo criança ou 
adolescente, além do aliciamento, assédio, instigação ou constrangimento da criança com o objetivo de com ela praticar ato libidinoso. Cumpre-se destacar que segundo o art. 241-E, da mesma lei, para efeito dos crimes, a expressão "cena de sexo explícito ou pornográfica" compreende qualquer situação que envolva criança ou adolescente em atividades sexuais explícitas, reais ou simuladas, ou exibição dos órgãos genitais de uma criança ou adolescente para fins primordialmente sexuais.

Nesse sentido, é de suma importância mencionar que o Código Penal Brasileiro também versa sobre a temática. Tipifica-se, além do estupro de vulnerável e a corrupção de menores, a divulgação de cena de estupro ou de cena de estupro de vulnerável:

Art. 218-C. Oferecer, trocar, disponibilizar, transmitir, vender ou expor à venda, distribuir, publicar ou divulgar, por qualquer meio - inclusive por meio de comunicação de massa ou sistema de informática ou telemática -, fotografia, vídeo ou outro registro audiovisual que contenha cena de estupro ou de estupro de vulnerável ou que faça apologia ou induza a sua prática, ou, sem 0 consentimento da vítima, cena de sexo, nudez ou pornografia. (grifos meus)

Faz-se relevante destacar que o crime, que inclui divulgação de cena com apologia ao estupro, e de cena de sexo, nudez ou pornografia sem consentimento, perpassa pela previsão no ambiente virtual, sendo taxativo no que diz respeito ao alcance "por meio de comunicação de massa ou sistema de informática ou telemática".

\subsection{DA INVESTIGAÇÃO CRIMINAL}

Tendo em vista que a materialização da análise em pauta teve como base o curso da fase inquisitorial da persecução criminal, há de se apresentar a apuração investigativa in casu, resguardando, contudo, o caráter sigiloso do material ${ }^{5}$.

5 Sob autorização de vista de inquérito oficialmente protocolada pela Corregedoria da Superintendência, deferida pelo Sr. Corregedor Maurício Salim Araújo, sob o número SEI 08255.005261/2019-54. 
O inquérito fora instaurado a partir de grande quantidade de imagens de cunho pedopornográfico encontrada em posse do investigado, segundo laudo de perícia criminal federal, que indicaram o envolvimento do indiciado em organização criminosa transnacional especializada no abuso de crianças e produção de conteúdo pornográfico infantil, "existindo ainda fortes indícios de que tal pessoa teria abusado da própria filha (na época, com 5 anos de idade) e registrado os abusos para compartilhamento com os demais integrantes da citada organização" Revela o despacho saneador:

[...] procurava produtores de material de abuso sexual infanto-juvenil, e afirmava ser o pai de uma criança brasileira de 6 anos, conhecida no meio pedófilo e que vinha sendo abusada há vários anos e cuja localização era considerada prioridade pela polícia federal. Conversas entre os usuários dos fóruns possuem níveis inimagináveis de perversão. Conversam sobre formas de abusar das crianças sem deixar marcas e sem que elas chorem, além de citarem medicamentos para acalmar as crianças de maneira a facilitar os estupros.

Este integraria rede internacional de abusadores/produtores de material pornográfico infanto-juvenil para a troca e disponibilização de arquivos na internet, segundo relatório encaminhado pelo Federal Bureau Investigation (FBI). Na lista de regras do cybergrupo, descrita como "teratológica" nos autos, se estabelece que "os novos usuários devem fazer uma validação para entrar, [...] um set ou vídeo customizado da menina que você quer introduzir".

A cooperação internacional se justifica pelo caráter transnacional do delito. A organização criminosa é conduta recorrente para tais fins, por motivos como a facilidade no meio cibernético, anonimato e até lucros financeiros, de forma a possibilitar o aperfeiçoamento e intensificação da prática.

Indica-se que há confissão do uso do TORCHAT, programa de mensagens instantâneas (própria para a rede TOR- da DeepWeb) que possibilita o envio de textos e arquivos de maneira segura (criptografada) e anônima. Contudo, o material fora identificado pelo banco de dados de imagens e vídeos de casos de abuso sexual infantil Internacional Child Sexual Exploitation (ICSE), estratégia comum nesse tipo de apuração. 
Segundo notitia criminis, o suspeito participava ativamente de Fóruns na DeepWeb, como de um que era administrado por um australiano, preso em 2014 e sentenciado a 35 anos de prisão por abuso de diversas crianças, incluindo um bebê de dezoito meses, além de crianças com transtornos e necessidades especiais.

\section{A “(CYBER)PEDOFILIA” E A PSIQUE}

A aproximação dos estudos psicanalíticos com desenvolvimento da criminologia fora pautada na contribuição com os seus fundamentos. A teoria psicanalítica do direito penal do criminólogo italiano Reik, por exemplo, aborda desconstrução do paradigma do perfil transgressor:

A tese de Reik sustenta dupla função à pena. [...] Em ambas as hipóteses segue a teoria freudiana do criminoso por sentimento de culpa. $O$ efeito catártico da pena e o processo de identificação da sociedade com o criminoso seriam os dois princípios básicos que possibilitariam a construção de teoria psicanalítica do direito penal. [...] Se a psicanálise, [...] na análise do sintoma social, possibilita a ruptura com a dicotomia entre o bárbaro e o civilizado, a psicanálise criminal ao indagar sobre a etiologia delitiva de pessoas honradíssimas e de elevada moralidade (Freud), contribui significativamente no fundamental processo de despatologização do crime e do criminoso (CARVALHO, 2018, p. 343).

Freud aprofundou-se na concepção do sujeito e suas subjetividades, ou na sua essência, como denominado no campo psicanalítico. A noção de que o inconsciente é um sistema psíquico regido por leis próprias precedeu a ideia de Lacan de que sua estrutura está atrelada à linguagem da ordem social, que antecede ao homem e o recobre de um mito construído pela referência. 


\title{
2.1 DA PEDOFILIA
}

Inicialmente, é indispensável salientar que o objeto da análise criminológica é a incidência do crime de Pornografia Infantil. Isso porque é costumeiro que se confunda essa espécie delituosa com a pedofilia, que por sua vez, não se trata de crime previsto em legislação vigente no país.

\begin{abstract}
A pedofilia, apesar de ser considerada uma patologia psiquiátrica, envolve importante aspecto sociocultural e é penalizada legalmente, através de pena de reclusão e multas, pois a ação de práticas pedofílicas corresponde ao dano ou risco de dano a outro, sendo a criança o agente passivo desta ação. (FERREIRA, 2015, p. 5)
\end{abstract}

A pedofilia consiste no desejo sexual desviante; é uma parafilia, um Transtorno de Preferência Sexual (TPS) segundo a Classificação Internacional de Doenças $10^{\text {a }}$ edição (CID-10). É uma perversão identificada pelo interesse sexual atípico por crianças, usualmente em fase pré-púbere ou no início da puberdade, caracterizando-se violência sexual pelo fato de que estas ainda não desenvolveram um mecanismo psíquico hábil a traduzir a invasão libidinosa do adulto perverso (MURIBECA; PEREIRA, 2013).

Tal perversão advém da inibição sexual do indivíduo, que escolhe o parceiro pela sua vulnerabilidade. Joel Birman (2002, p. 40) conclui, portanto, que "a criança nunca é parceira na relação de um pedófilo, mas seu objeto, pois é um ser indefeso, dominado sadicamente".

Pelo fato de que se trata de uma disfunção, surge, ainda, uma errônea compreensão de que os chamados pedófilos são cidadãos incapazes de lidar com seus sintomas. A perspectiva freudiana esclarece e sinaliza que por motivos estéticos, atribuiu-se as "aberrações" graves da pulsão sexual à loucura, mas nega que isso seja possível, pois, na prática, essas perturbações são encontradas também naqueles sadios. Isso significa que o crucial, na realidade, é a questão do descontrole de seus impulsos e oportunidade de satisfazê-los. 


\subsection{DA (IN)CAPACIDADE PENAL}

Pelo critério misto (biopsicológico) adotado pelo Código Penal Brasileiro, levanta-se a possibilidade de caracterização de inimputabilidade aos sujeitos ativos do crime investigado. Vejamos o disposto no artigo 26:

Art. 26 - É isento de pena o agente que, por doença mental ou desenvolvimento mental incompleto ou retardado, era, ao tempo da ação ou da omissão, inteiramente incapaz de entender o caráter ilícito do fato ou de determinar-se de acordo com esse entendimento. (grifos meus)

Observa-se que desequilíbrio do trato mental não é requisito único para o cabimento, sendo necessário que este transtorno impossibilite, efetivamente, a capacidade de compreensão do ilícito (NUCCl, 2011).

Na visão de McDougall (1997), o perverso é aquele indivíduo totalmente indiferente às necessidades e desejos do outro. Mesmo sendo uma patologia, o pedófilo preserva o entendimento de seus atos, impondo seus desejos e condições pessoais a alguém que não deseja ser incluído em sua fantasia sexual (MURIBECA; PEREIRA, 2013, p. 27).

Todavia, a médica legista e sexóloga criminal Mariana da Silva Ferreira explica que apenas $20 \%$ dos agressores têm diagnóstico do transtorno, e completa afirmando que reconhecê-lo como doente é fazê-lo se beneficiar legalmente ${ }^{6}$. Tratase de um deslocamento da atenção dos atos criminosos - com raízes etiológicas na conduta de homens não doentes, mas mergulhados em uma misoginia cultural - para de supostos sujeitos anormais (LOWENKRON, 2013).

Com isso, as controvérsias sobre a inimputabilidade do pedófilo se tornam secundárias ao observarmos que, in casu, os indiciados pelo crime de pornografia não teriam sequer praticado os atos ilícitos sob condição da enfermidade.

\footnotetext{
${ }^{6}$ UOL. Violência contra a Mulher. "Ela atende vítimas de estupro no IML, de bebê de dias a senhora de 80 anos",2019. Disponível em: https://www.uol.com.br/universa/noticias/redacao/2019/09/30/sexologacriminal-do-iml-ja-atendi-bebe-de-7-dias-a-senhora-de-80-anos.htm, acesso em: 01/09/2019.
} 


\section{A PORNOGRAFIA INFANTIL SOB PERSPECTIVA DE GÊNERO}

Estamos diante de um cenário onde o mercado mundial da pornografia infantil movimenta mais de $\mathrm{R} \$ 4$ bilhões de reais por ano, segundo dados da Interpol, ocupando o Brasil o $4^{\circ}$ lugar no ranking dos países que a exploram (SANTO, 2015).

Em paralelo, dentre as 76.171 mil denúncias de violência sexual contra crianças e adolescentes, as meninas são vítimas majoritárias, na faixa etária de 4 a 11 anos, sendo estas violentadas preponderantemente em sua própria casa ou grupo familiar ${ }^{7}$. Isso indica que a grande maioria dos algozes, são pessoas que detinham função moral e social de proteger a dignidade desses alvos (MIRANDA; SANTO, 2012), mas se utilizam de sua posição de poder ou autoridade para satisfazer-se sexualmente (MOLTEDO; MIRANDA, 2004).

\subsection{DO MATERIAL PORNOGRÁFICO}

A própria pornografia por si só, é um fenômeno crescente nas sociedades pós-modernas, e carrega consigo uma gama vasta de informações que direta ou indiretamente, afetam os seus expectadores. Tem-se tornado cada vez mais evidente que ela gera um impacto significativo na estrutura psicossocial do sujeito que mantêm contato com o material pornográfico.

Nessa ambiência, faz-se relevante citar a relação dos estímulos sexuais promovidos pela pornografia e sua potencialidade de gerar estímulos violentos. A obra "A Cidade Perversa", aborda o sujeito sadeano ${ }^{8}$, que independentemente de hiperburguês ou consumidor proletarizado, dedica-se ao gozo excessivo.

Dufour considera [...] que houve uma passagem de uma primeira a uma segunda transgressão: a primeira diz respeito ao que se define classicamente como perversão, ou seja, como algo que, justamente por ser transgressão, só pode ser entendido a partir da lei; e a segunda, apesar

\footnotetext{
7 CHILDHOOD BRASIL. "Nossa Causa". Disponível em: https://www.childhood.org.br/nossa-causa, acesso em 28/08/2019.

8 Referência ao Marquês de Sade, aristocrata francês e escritor libertino que deu origem ao termo "sadismo", que define a perversão sexual de ter prazer na dor física ou moral do parceiro ou parceiros.
} 
de portar o mesmo nome, rompe no entanto com a relação necessária com a lei e se abre para o sem-limite, por força do que Dufour chama a uma certa altura de desinibição pulsional, que conduz à servidão do homem liberado. (DUFOUR, 2013, p. 4)

A mencionada influência, já consideravelmente estudada no âmbito da neurociência, e difundida no campo da Sociologia, se torna palpável com declarações como as de Ted Bundy, psicopata e assassino confesso de mais de 35 mulheres e suspeito de mais outros cem crimes sexuais, que atribuiu múltipla abertamente esse padrão comportamental violento ao vício em pornografia9:

Eu não sou nenhum cientista social, [...] mas eu vivi na prisão por um longo tempo, e eu conheci um monte de homens que eram motivados a cometer violência. Sem exceção, cada um deles estava profundamente envolvido com pornografia - profundamente consumidos pelo vício.

Nesse sentido, uma pesquisa recente ratificou que a violência contra a mulher no âmbito da pornografia configura mais regra do que exceção:

Analisaram o conteúdo de 304 cenas de vídeos pornográficos mais populares. Os resultados indicaram que $88 \%$ das cenas apresentavam agressão física e $49 \%$ agressão verbal. As formas de violência mais comumente observadas foram espancamento (75\%), engasgos durante a prática de sexo oral no homem (54\%), insultos $(49 \%)$, tapas (41\%), puxões de cabelo (37\%) e sufocamento (28\%). Os perpetradores eram homens em $70 \%$ dos casos, e em $94 \%$ dos casos, as mulheres eram o alvo da agressão. (BRIDGES ET AL, 2010, p. 1065)

Tal cunho violento se manifesta não só no produto da indústria pornográfica, mas na sua própria manutenção. $\mathrm{O}$ machismo dos bastidores, onde a maior parte dos trabalhadores são homens ${ }^{10}$, acaba por submeter as mulheres à opressão, produzindo um conteúdo igualmente degradante e violento que reforça e

9 ROSSI, Rafael. "Criminalidade e Pornografia: O caso de Ted Bundy". 2016. Disponível em: http://vicioempornografiacomoparar.com/3256-2/, acesso em: 15/05/2019.

10 REDAÇÃO HYPENESS. "Vídeo denuncia condição das mulheres na indústria pornográfica". Disponível em: https://www.hypeness.com.br/2017/07/video-denuncia-condicao-das-mulheres-naindustria-pornografica/, acesso em 23/09/2019. 
banaliza essa representação da desigualdade de gênero, semeando a ideia de que na sexualidade, se inclui o comportamento abusivo contra a mulher (D'ABREU, 2013).

A pedido do canal SexyHot, o Quantas Pesquisas e Estudos de Mercado coletou dados ${ }^{11}$ para fins de traçamento de perfil do público brasileiro de pornografia. 22 milhões deles assumem o consumo, totalizando $76 \%$ homens, majoritariamente jovens (58\% têm menos de 35 anos), de classe média alta (49\% pertencem à classe B) e comprometidos (69\% são casados ou estão namorando), além de que $49 \%$ concluiu o ensino médio e $40 \%$ tem curso superior. Como principal "motivador" para os acessos, fora apontado o interesse em "ver e aprender situações/posições", o que significa que a pornografia é uma "pílula de estímulo" e "dá vazão a fantasias, desejos, frustrações e permite viver o prazer livre que hoje se concretiza em imagens".

A problemática se dá, portanto, quando estímulos não-saudáveis viram paradigma para relação sexual. O conteúdo pornográfico de alta circulação, hoje, tem como base na supervalorização da vulnerabilidade da mulher e do corpo feminino. A lógica do consumo, em sua conotação destrutiva, segue a perspectiva vexatória, de imposição do papel subalterno da mulher, pois é o que excita o público-alvo.

\subsection{DOS ASPECTOS CULTURAIS}

Como questão histórico-cultural, inerente ao tempo presente, o tratamento que se dá a tais comportamentos tem raízes nas constantes mudanças sociais. Em cada ciclo, cada geração, nos deparamos com novas formas de enxergar subjetividades coletivas imprescindíveis para o convívio humano, adaptando as nossas visões de moral e ética, por exemplo. A respeito da temática do consumo da pornografia, exposta alhures, faz-se relevante desmembrar o que se chama de "cultura da pedofilia": no que tange aos padrões de beleza femininos, a aproximação estética com a aparência infantil é a regra, mesmo para as mulheres maduras.

Teresa Tsang (2015), ao abordar como essa cultura afetou a forma como vemos a beleza feminina, cita as políticas anti-envelhecimento que tem as mulheres

${ }^{11}$ MURARO, Cauê. G1. "22 milhões de brasileiros assumem consumir pornografia e 76 são homens, diz pesquisa". 2018. Disponível em: https://g1.globo.com/pop-arte/noticia/22-milhoes-de-brasileirosassumem-consumir-pornografia-e-76-sao-homens-diz-pesquisa.ghtml, acesso em: 20/06/2019. 
como público alvo, como a obsessão pelo fim dos pelos e das rugas. Enfatiza, inclusive, a ascensão de um tipo de cirurgia chamado labioplastia, que consiste na redução dos lábios mínimos - em vaginas consideradas normais, atribuindo à influência da vulva pornesque, a percepção deturpada da própria aparência. Ela defende que a pornografia tem provado moldar as preferências das pessoas, já que nossos cérebros são mutáveis e podem ser condicionados devido à neuroplasticidade. Para ilustrar sua tese, cita que por dois anos consecutivos, (2013 e 2014), a categoria de pornografia mais popular no PornHub era Teen (em português, adolescente). Em 2013, o portal G1 de notícias publicou uma matéria que dizia que o mesmo site teria anunciado que o termo "novinha" foi um dos mais buscados por brasileiros ${ }^{12}$.

Laura Lowenkron (2013, p. 326-327) reforça a existência dos muitos sítios pornográficos na internet nos quais a menoridade, principalmente a feminina, é simulada, por ser valorizada no mercado do erotismo enquanto "fantasia sexual" masculina, e completa:

São meninas bem jovens com corpos magros, seios pequenos, poucas curvas, pelo pubiano ralo ou depilado, usando roupas e representando performances infantis que fazem o estilo "Lolita", ou seja, inocentes, porém provocantes.

O apreço do público masculino pela juventude é notório, o que confirma que maioria desses homens não são pedófilos, e sim indivíduos com tal comportamento resultante de profundo condicionamento cultural. Desta forma, observa-se que àqueles investigados pelo crime de Pornografia Infantil na PF/BA, por analogia, não tem interesse sexual especificamente no corpo da criança pré-púbere, como têm os pedófilos diagnosticados. O que essas vítimas têm a oferecer aos seus algozes é a sua posição de vulnerabilidade, sendo ela, portanto, a origem do "fetiche". Trata-se de um desejo por essa posição hipossuficiente levada ao nível extremo, especialmente quando analisamos os inquéritos que têm meninas como vítimas, os quais são, sem surpresas, a maioria.

12 G1, São Paulo. "Em site pornô, 'Novinha' foi um dos termos mais buscados por brasileiros". 2013. Disponível em: http://g1.globo.com/tecnologia/noticia/2013/12/em-site-porno-novinha-foi-um-dos-termos-maisbuscados-por-brasileiros.html, acesso em 14/06/2019. 


\subsection{DOS ASPECTOS HISTÓRICOS}

Os direitos sexuais têm emergido gradativamente como objetos de tutela e proteção, perpassando por um aspecto muito presente nas pautas pós-modernas: a liberdade sexual. Questões como os limites da interferência do desejo sexual alheio e o respeito à dignidade sexual no tocante à diversidade de orientação sexual e gênero, estão cada vez mais presentes no fenômeno coletivo. Deste modo, elas tendem a ressoar na atuação legal e jurídica, adaptando-se e ressignificando tais normatizações.

Tratando-se de uma era tecnológica, é indispensável que se analise o rompimento com a dignidade sexual também em contexto virtual. Como exemplo, a Lei 12.015/09, alterou a redação do Código Penal brasileiro de forma a ampliar as possibilidades de consumação inequívoca da forma do estupro virtual. Mais recentemente, a Lei 12.737/2012, conhecida como "Lei Carolina Dieckman" tipificou delitos informáticos ligados à experiência da atriz, que em 2011, teve fotos e conversas em situação íntima "vazadas" por hacker, de seu aparelho pessoal.

O espaço virtual tem sido, também, ambiente favorável à disseminação de denúncias. A campanha \#meuprimeiroassédio surgiu como reação à comentários sexuais na internet sobre uma menina de 12 anos, participante do programa de tv MasterChef, trazendo delimitação de faixa etária à discussão:

Em 2015, a \#meuamigosecreto ganhou notoriedade nacional, agindo em enfrentamentos e abrindo espaço para uma discussão responsável e assertiva acerca de violências naturalizadas sofridas pelas mulheres cotidianamente. Dois anos depois, mulheres protagonizaram a capa da revista norte americana Times, graças a uma outra campanha em formato de hashtag, a \#MeToo, também denunciadora de agressões e abusos (CAVALCANTI; MENEZES, 2018, p.16).

Com o fenômeno digital e a nova forma dos relacionamentos entre jovens, surgem representações e performances sexuais atreladas a essas novas tecnologias de comunicação. Exemplo disso é a prática da troca de imagens de cunho 
erótico, em contexto de sexting ${ }^{13}$, que mesmo consensual ramificou-se em uma exposição criminosa, desnudando machismo, reminiscência da estrutura patriarcal, sexualização e objetificação do corpo feminino, dizendo respeito à pornografia de vingança (CAVALCANTI; MENEZES, 2017; 2018).

Fica claro que a compreensão acerca das minúcias que envolvem as relações interpessoais no cyber espaço é ressignificada no que se refere ao uso da internet pelos jovens, visto que é muito mais disseminada e familiar para essa geração, consequentemente a expondo mais a relativização dos âmbitos pessoal e privado e da exposição exacerbada de si.

\subsection{DOS OLHARES FEMINISTAS}

Diante das constatações, se torna inexorável a abordagem do fenômeno sob a perspectiva feminista. Isso porque, possibilitou-se partir do pressuposto de que a incidência de violências sexuais está diretamente atrelada à opressão sofrida pelas mulheres (e, no caso, meninas), decorrente do patriarcado que domina a categoria "mulher" tanto pelos traços biológicos quanto aspectos socialmente construídos, vitimando-as pela sua "womanhood"14. (PISCITELLI, 2002, p. 4-5)

Nesse contexto, a produção e consumo de pornografia infantil no contexto global resguarda origens etiológicas comuns ligadas à exploração feminina baseada em uma lógica de manutenção de violências sobrepostas (CAVALCANTI, 2018). Isso significa um aumento da vulnerabilidade das mulheres, pela demanda do consumo misógino que se excita com a sobreposição de características hipossuficientes, como no caso, envolve o gênero feminino somado a condição de criança ou adolescente. Dá-se assim, o que Laura Lowenkron (2010, p.16) chama de "ênfase na assimetria do poder", sob a ótica da antropologia social.

Em nota técnica publicada pelo IPEA (2014, p.7) sobre estupro no Brasil [...] $89 \%$ das vítimas são do sexo feminino, [...] e que as crianças e adolescentes representam mais de $70 \%$ das vítimas.

13 " $A$ atividade de enviar mensagens de texto que tratam de sexo ou que pretendem excitar sexualmente alguém" em tradução livre da definição do Cambridge Dictionary.

14 "Feminilidade" em tradução livre. Referência direta ao fato de serem mulheres. 
Pode-se observar onde as origens do comportamento do algoz frente às mulheres e às crianças se entrelaçam, constatando as semelhanças de ambos os fatores definidores da práticas do abuso sexual. Evidencia-se relação de poder do abusador para com o abusado, e a impossibilidade das crianças e dos adolescentes conscientemente consentirem com prática do ato (CANEZIN; PEROZIM; 2010). Similarmente, no abuso que advém da discriminação de gênero - a exemplo da violência doméstica - também reina a forte influência dessa relação de poder, que se materializa, aqui, no sentido da dependência financeira e/ou da subalternização da autonomia da vontade da vítima.

Para além do sustento financeiro, Hilda Nascimento (2001) aponta a frequência em que a vítima vive sobre o mesmo teto do abusador. Tal questão, além de estar atrelada às origens patriarcais da violência doméstica, se correlaciona com a incidência do abuso sexual como manifestação incestuosa, no caso da "pedofilia". Este elemento serve para corroborar com a maior vulnerabilidade que se têm quando o ambiente doméstico-familiar é palco de violações de direitos sexuais, justificando os $79 \%$ de casos de estupro de crianças ocorrendo dentro de suas residências, além de que, quando um agressor/autor é um familiar, a chance de recorrência da violência é quase quatro vezes maior do que se este não for seu parente (IPEA, 2014, p.12).

No que tange à violação de direitos sexuais das mulheres em espaço virtual, também é possível realizar conexões com as vítimas infanto-juvenis. Isso porque, a intensificação das relações digitais promove uma exposição imagética com amplidão que ofende, constrange e intimida, pois é a imagem feminina a mais divulgada, repercutida e consequentemente ridicularizada no lugar de objeto de desejo sexual de outrem, criando associações pessoas-produto, dominaçãosubordinação e fetichização das relações interpessoais (MENEZES; CAVALCANTI, 2017).

Assim, o homem encontra na internet um espaço fértil para o exercício do seu estigma de virilidade e dominação, de forma a contribuir com a socialização de ordem patriarcal que os conduz à essa sobreposição e posse em relação ao corpo da mulher, em contraponto à ela, que é conduzida ao comportamento dócil, casto e cordato (SAFFIOTI, 2004). 
Destarte, o abusador transforma a sexualidade de outrem - tanto da mulher adulta quanto da criança/adolescente - em objeto para satisfação de seus desejos (FERREIRA, 2017). O medo da repercussão da denúncia da violência também faz parte das consequências psicológicas comuns para ambos os perfis de vítimas, pelo medo do descrédito e da não proteção, e por isso, mantêm em segredo o fato de forma consciente (BALBINOTTI, 2009, p.8). Elas tendem a se sentirem culpadas, com ódio de si mesmas, crendo que foram elas que provocaram e permitiram o abuso sexual (FERREIRA, 2017).

No campo da vitimologia, Antônio Berisntain (2000, p.105) consolida o entendimento:

Ao longo do processo penal [...] os agentes de controle social, com frequência se despreocupam com (ou ignoram) a vítima; [...] especialmente em alguns delitos, como os sexuais. Não é raro que nessas infrações o sujeito passivo sofra repetitivos vexames, pois a agressão do delinquente se vincula a postergação e/ou estigmatização por parte da polícia, dos médicos forenses e do sistema judiciário.

Servil ao patriarcalismo, fundamento da estrutura autoritária da sociedade burguesa, a teoria positivista promove uma espécie de "legitimação do ilegitimável", de forma a obscurecer questões cruciais ao direito penal e criminal especialmente no âmbito das transgressões de cunho sexual.

A criminologia feminista desmistifica a ideia de que a violação sexual acontece longe de todos, [...] impulsionada por uma libido incontrolável que se manifesta em um ser rude e perverso. Ao contrário, [...] normalmente acontece no quarto ao lado, como manifestação material da opressão de gênero, como forma de marcar o poder de domínio do homem sobre a mulher (WEIGERT; CARVALHO, 2019, p. 22).

\section{CONCLUSÃO}

A impressão que se tem pela pesquisa empírica, por fim, é que quando se trata da intervenção combativa do estado, em especial na atuação de seus agentes, 
- obscurantismo acerca das questões cruciais desvendadas ao longo da análise científica é inegável. Resguardando a sagrada família, como clama o seu próprio hino, a equipe da Polícia Federal, em sua esmagadora maioria - masculina, tem uma compreensão muito superficial quanto à influência do gênero na perpetuação das violências sexuais.

O tratamento do tema como "causa política" é fator determinante para a incompreensão da realidade do mesmo. Ficamos à mercê de um enfrentamento baseado em uma ideia de moral que distorce a causa. Deste modo, a comoção suscita confiança para um engajamento vazio, que movimenta o "cidadão de bem" contra condutas resultantes dos seus próprios traços socioculturais conservadores, antiemancipatórios e, consequentemente misóginos.

Ao investigar o predomínio da figura masculina como autor e feminina como vítima nos casos de abuso de menores, a abordagem neuropsicológica não se mostra eficaz para desvendá-lo, visto que as pesquisas limitadas a esse campo não trazem essa preocupação. Isso porque, segundo a linha investigativa aqui estabelecida, a resposta não se encontra na ciência "objetiva", mas sim em aspectos etiológicos oriundos de questões sociais subjetivas como ante exposto, atreladas à misoginia cultural.

Revelando-se estrutural, o problema demanda múltiplas medidas de intervenção, para que se resulte em profundas mudanças sociais. Além da adaptabilidade da norma e, em especial de seus operadores, há de se destacar a importância do intuito preventivo, à começar pelos esforços no sentido de fortalecimento de políticas públicas e outras instrumentalizações estatais à serviço do aparelhamento educacional como meio intersetorial de mitigação das questões envolvidas, pautado nas premissas dos direitos humanos.

Ocorrendo as violações sexuais geralmente dentro de casa - como restringir, como espera o conservadorismo, a educação infantil aos pais, se é nas mãos deles que seus filhos (ou filhas, no caso) são violados? É preciso desprenderse das lacunas com relação a determinadas temáticas em sexualidade, que a reduz ao aspecto meramente genital, reforçando a compreensão falocêntrica da relação, e dificultando ainda mais o processo de conscientização e prevenção das violências sexuais, em especial à cyberpedofilia. 


\section{REFERÊNCIAS}

BAILEY, Frederick George. The tactical uses of passions. Ithaca and London, Cornell University Press, 1983.

BALBINOTTI, Cláudia. A violência sexual infantil intrafamiliar: a revitimização da criança e do adolescente vítimas de abuso. Direito \& Justiça. Porto Alegre, v. 35, n. 1 , p. 5-21, jan./jun. 2009. Disponível em: http://revistaseletronicas.pucrs.br/ojs/index.php/fadir/article/download/8207/5894, acesso em: 27/07/2019.

BERISTAIN, Antônio. Nova Criminologia a luz do Direito Penal e da Vitimologia. Editora UNB, $2000-1^{\circ}$ Edição.

BIRMAN, Joel. Inocência roubada. Revista Superinteressante, n.176, p. 39-46, maio 2002.

BRIDGES, A. J., WOSNITZER, R., SCHARRER, E., SUN, C., \& LIBERMAN, R. Aggression and sexual behavior in best-selling pornography videos: $A$ content analysis update. Violence against Women, 16, 2010, p. 1065-1085. Disponível em: https://pdfs.semanticscholar.org/db43/7a7a4a975603690bd5921286c7831b487d10.p df, acesso em: 12/08/2019.

CANEZIN, Claudete; PEROZIM, Ana Carolina. Do Crime de Abuso Sexual Praticado Contra Crianças e Adolescentes e Depoimento Sem Dano. Revista IOB de Direito de Família. Ano 11, n.57 (dez./jan. 2010)

CARVALHO, Salo de. Anti-manual de Criminologia. São Paulo: Saraiva, 2015.

CAVALCANTI, Vanessa Ribeiro Simon. Violência(s) sobreposta(s): Contextos, tendências e abordagens num cenário de mudanças. In: DIAS, Isabel (Org.). Violência doméstica e de gênero: Uma abordagem multidisciplinar. Lisboa: Pactor, 2018, v. 1, pp. 97-122.

CAVALCANTI, Vanessa Ribeiro Simon \& SILVA, Antonio Carlos. Diálogos abertos e Teoria Crítica: por uma "aventura emancipatória". Revista Dialética, vol. 6, junho de 2015 ,

pp.

66-78.

CAVALCANTI, Vanessa Ribeiro Simon \& SILVA, Antonio Carlos. Em que ponto estamos: urgências, emergências e pautas de educação e direitos humanos. In: Flávio Romero Guimarães, Paulla Christianne da Costa Newton, Ricardo dos Santos Bezerra. (Org.). Direitos Humanos: Desafios e perspectivas no mundo contemporâneo. Campina Grande: Editora da Universidade Estadual da Paraíba/Realize, 2018, v. 1, pp. 98-108.

D'ABREU, Lylla Cysne Frota. Pornografia, desigualdade de gênero e agressão sexual contra mulheres. Psicol. Soc., Belo Horizonte, v. 25, n. 3, p. 592-601, 2013. Disponível em: http://www.scielo.br/scielo.php?script=sci_arttext\&pid=S010271822013000300013\&lng=en \&nrm=iso, acesso em: 06/08/2019.

DUFOUR, Dany-Robert. A Cidade Perversa - Liberalismo e Pornografia. Rio de Janeiro: Civilização Brasileira, 2013 - $1^{\underline{a}}$ ed. 
ESTEVAO, Carlos V.. Democracia, justiça e direitos humanos: 'pontos cegos' do discurso humanista na era dos mercados. Rev. Port. de Educação, Braga, v. 26, n. 2, p. 179-203, $2013 . \quad$ Disponível em: http://www.scielo.mec.pt/scielo.php?script=sci_arttext\&pid=S0871-

91872013000200009\&lng=pt\&nrm=iso, acesso em 29/10/2019.

FERREIRA, Laís Pires. A Proteção da Criança ou Adolescente Vítima de Abuso Sexual como justificativa para Flexibilização da Regra

Impeditiva da Adoção por Avós. Tese (Graduação em Direito) - Faculdade Baiana de Direito, Salvador. 2017.

FERREIRA, Mariana da Silva. Pedofilia: Aspectos Etiológicos. Tese (PósGraduação Latu Sensu em Sexualidade Humana) - FMUSP, São Paulo. 2015.

FREUD, Sigmund. (1856-1939) Totem e Tabu: algumas concordâncias entre a vida psíquica dos homens primitivos e a dos neuróticos. São Paulo: Penguin Classics Companhia das Letras, $2013-1^{1 \underline{a}}$ ed.

FREUD, Sigmund. (1901-1905) Três ensaios sobre a teoria da sexualidade. In: Obras psicológicas completas: Edição Standart Brasileira. Vol. VII. Rio de Janeiro: Imago, 1996.

GRANGEIA, Mario Luis. Três parcerias do Ministério Público com ONGs: novos diálogos entre Estado e sociedade. Política \& Sociedade. v. 12, n. 23. 2013. p. 6795.

INSTITUTO BRASILEIRO DE PESQUISA ECONÔMICA APLICADA. Estupro no Brasil: Uma Radiografia Segundo os Dados da Saúde. Brasília: IPEA n 11, 2014.

KEULS, Eva.The Reign of the Phallus: Sexual Politics in Ancient Athens. New York: Harper \& Row, 1985.

LACAN, J. (1988). O Seminário: Livro 11: Os quatro conceitos fundamentais da psicanálise. Rio de Janeiro: Zahar. (Seminário proferido em 1964).

LEVY, Pierre. 2009. Cibercultura. São Paulo: Editora 34.

LOWENKRON, Laura. Abuso sexual infantil, exploração sexual de crianças, pedofilia: diferentes nomes, diferentes problemas? Revista Latinoamericana Sexualidad, Salud y Sociedad. Rio de Janeiro: Centro Latinoamericano em Sexualidad y Deretchos Humanos, $n^{\circ}$ 5, 2010, p.9-29.

LOWENKRON, Laura. O monstro contemporâneo: notas sobre a construção da pedofilia como "causa política" e "caso de polícia". Cad. Pagu, Campinas, n. 41, p. 303-337, 2013. Disponível em: http://www.scielo.br/scielo.php?script=sci_arttext\&pid=S0104$83332013000200016 \&$ Ing =en\&nrm=iso, acesso em 20/09/2019.

MCDOUGALL, Joyce. Las mil y una caras de Eros. Buenos Aires: Ed. Paidós, 1998. 
MENEZES, Mariana Risério Chaves de. Juventudes, representações e tecnologias: uma etnografia acerca da exploração da imagem feminina na cibercultura. 2018. 124. Dissertação. (Mestrado em Família na Sociedade Contemporânea) - Universidade Católica do Salvador - UCSAL, Salvador, 2018.

MENEZES, Mariana Risério Chaves de; CAVALCANTI, Vanessa Ribeiro Simon. Mulher jovem e a cibercultura: liberdade, subordinação e reminiscências patriarcais no meio virtual. Ex Aequo (Oeiras). v. 35, p. 33-47, 2017.

MIRANDA, Rafael Martins de.; SANTO, Eniel do Espírito. Abordagem neuropsicológica do abuso sexual: conhecendo o que está por trás do predomínio de gênero do abusador. Revista Saúde e Desenvolvimento. v. 1 - № 1, P. 86-106, 2012.

MOLTEDO, C.; MIRANDA, M. Protegiendo los deretchos de nuestros niños y ninãs: prevención del maltrato y el abuso sexual em el espacio escolar: manual de apoyo para professores. Santiago, Chile: Edición Fundación de la Familia \& Ministério de la Justicia, 2004.

MURIBECA, Maria das Mercês Maia; PEREIRA, Wagner da Matta. Quando o lobo e o cordeiro perdem a pele: a psicanálise na escuta da pedofilia. Cogito, Salvador, v. 14, p. 24-28, nov. $2013 . \quad$ Disponível em: http://pepsic.bvsalud.org/scielo.php?script=sci_arttext\&pid=S 151994792013000100006\&lng=pt\&nrm=isso, acesso em 29/10/2019.

NASCIMENTO, Hilda Angélica de Lucas. A Criança como Vítima de Crime. IN: SÉGUIN, Elida (Org.). Aspectos Jurídicos da Criança. Rio de Janeiro: Lumen Juris, 2001.

NUCCI, Guilherme de Souza. Manual de Direito Penal - Parte Geral - Parte Especial. Revista dos Tribunais, $2011-7^{\mathrm{a}} \mathrm{ed}$.

PALOMBA, Guido Arturo. Tratado de psiquiatria forense, civil e penal. São Paulo: Atheneu Editora, 2003.

PISCITELLI, Adriana. Recriando a (categoria) mulher? In: ALGRANTI, L. (Org.). A prática feminista e o conceito de gênero. Textos Didáticos, n. 48. Campinas: IFCH/Unicamp, 2002, p. 7-42.

ROSSI, Rafael. Criminalidade e Pornografia: O caso Ted Bundy. 2016. Disponível em: http://vicioempornografiacomoparar.com/3256-2/, acesso em 14/06/2019.

SAFFIOTI, Heleiete. 2004. Gênero, Patriarcado, Violência. São Paulo: Fundação Perseu Abramo.

SANTO, Kleber Assunção do Espírito. Crimes Cibernéticos. Tese (Universidade Tuiuti do Paraná). Curitiba, 2015. 
SILVA, Salete Maria. Feminismo Jurídico: (des)conhecido e (des)necessário? SINTAJ, Bahia. 2018. Disponível em: https://sintaj.org/artigo/feminismo-juridicodesconhecido-e-desnecessario/, acesso em: 29/10/2019.

TOREZAN, Zeila C. Facci; AGUIAR, Fernando. O sujeito da psicanálise: particularidades na contemporaneidade. Rev. Mal-Estar Subj., Fortaleza, v. 11, n. 2, p. 525-554, $2011 . \quad$ Disponível em <http://pepsic.bvsalud.org/scielo.php?script=sci_arttext\&pid=S1518$61482011000200004 \&$ lng=pt\&nrm=iso $>$. acesso em 29 out. 2019.

TSANG, Teresa. How Pedophile Culture Has Affected How We See Beauty - (Why do grown women want to feel and look like they did when they were younger?). Odyssey, 2015. Disponível em: https://www.theodysseyonline.com/pedophile-culture, acesso em 29/05/2019.

VIEIRA, Priscila Mugnai; MATSUKURA, Thelma Simões; VIEIRA, Camila Mugnai. Políticas públicas e educação sexual: percepções de profissionais da saúde e da educação. Revista Internacional Interdisciplinar INTERthesis, Florianópolis, v. 14, n. 3 , p. 69-87, set. 2017. ISSN 1807-1384. Disponível em: https://periodicos.ufsc.br/index.php/interthesis/article/view/1807-1384.2017v14n3p69, acesso em: 24/10/2019.

WEIGERT, Mariana de Assis Brasil; CARVALHO, Salo de. Criminologia feminista com criminologia crítica: perspectivas teóricas e teses convergentes. Revista Direito e Práxis, Ahead of Print, Rio de Janeiro, 2019. 